\title{
DIPHTHERIA, ITS EXTENT AND FATALITY IN THE LARGE PROVINCIAL TOWNS OF ENGLAND AND WALES, AND IN THE HOSPITALS OF THE METROPOLITAN ASYLUIIS BOARD, DURING THE YEARS 1894-1904 INCLUSIVE, IN RELATION TO THE USE OF ANTITOXIC SERUMI IN THE TREAT- MENT OF THE DISEASE.
}

BY HENRY E. ARMSTRONG, D.HY.

Medical offeer of Health, Newcastle-upon-Tyne.

THE following tables have been prepared from : (a) Statistics of notified cases of the disease, courteously furnished by the Medical Officers of Health of the large provincial cities and towns; $(b)$ the Registrar General's Annual Summaries of Deaths; (c) the Annual Reports of the Metropolitan Asylums Board. The object of the Tables is to show as fully as possible the extent and annual fatality (actual and relative) of Diphtheria in England and Wales since the introduction of Antidiphtheritic Serum in the treatment of the disease. This object is to some degree frustrated by the want of definite information as to the precise dates at which the serum came into use in the respective provincial towns, and the relative extent of its employment in each. It is also affected by the question of probably increased accuracy of diagnosis in recent, as compared with earlier, years. Apart from these points, certain facts stand out prominently in the tables, viz. :-

1. That during the eleven years ended 1904, 64,498 cases of diphtheria have been treated in the hospitals of the Metropolitan Asylums Board, and 95,692 have been notified in the 31 large English towns named in Table I., making a total of 160,190.

2. That the deaths from diphtheria in the above period have been as under, viz. :-

$\begin{array}{cccc}\text { In Metropolitan Asylums Board Hospitals } & \ldots & 9,512 \\ \text { In 31 large provincial towns .. } & . . & . & \frac{18,869}{28,381} \\ \text { Total } & . & \ldots & \end{array}$

These figures represent a mortality rate per cent of $17 \cdot 7$

3. That diphtheria (as notified) has during recent years shown a greatly increased general prevalence in the large urban districts of England and Wales, the maximum for the 31 towns (12,721 cases) having occurred in the year 1900 , since which a gradual reduction has 
taken place (see Table I). The numbers during the latter half of the period, however, greatly exceed those of the former half. This prevalence is for the most part due to the increase of the disease in certain towns only (as shown in paragraph 5).

4. That the above increase is only in small part, if at all, to be explained by the growth of the populations in the towns in question. Thus, apart from the periods of greatest prevalence, the total number of cases in the last of the eleven years in question $(9,553)$, is more than double that of the first year $(4,535)$. The average yearly number of notifications in these provincial towns during the five years 1894-1898 inclusive is 5,625, and during the six years immediately following 11,261. These figures denote a rate of inerease of the disease out of all proportion to that of the population.

5. That the foregoing increased prevalence has been chiefly due to epidemics in some sixteen of the large towns, lasting for the most part for three or more years. These outbreaks are indicated in Table I. by italic type.

6. That in the London hospitals the number of cases for the five years 1894-98 inclusive averaged 4,809 per annum, and in the six years 1899-1904 inclusive 6,742 per annum.

7. That in the 31 provincial towns specified the mean death rate per cent to cases of diphtheria has fallen (see Table III.) from 30.5 and 33.1 in 1894 and 1895 respectively, to 17.7 and 18.0 in 1903 and 1904 respectively. This reduction has for the most part been steady and gradual. The individual mortality rates of the respective towns in the table cannot be satisfactorily summarized in detail here. They show, however, the remarkable fact that during the first four of the years under report the death rate per cent of cases from diphtheria in one or other of seven of the towns reached a maximum of from 50.0 to $61 \cdot 1$ per cent; and that during the last four years it fell in four towns to a minimum of from 6.5 to 3.6 per cent. In the Metropolitan hospitals (see Table IV.) the mortality has fallen from 29.3 per cent in 1894 to $10^{\circ} 0$ per cent in 1904 .

8. That the reduced fatality of diphtheria in the Metropolitan hospitals coincides with the introduction of antitoxin, which was first employed to a slight extent in the treatment of the disease towards the close of 1894, after which the fall in the death rate was marked. The direct effect of antitoxin in the reduction of the mortality in the large provincial towns (see Table III.), although doubtless largely contributory to this result, cannot be so accurately gauged as in London, owing to the want of information as to the extent of its use, either in hospital or in private practice, in these towns. 


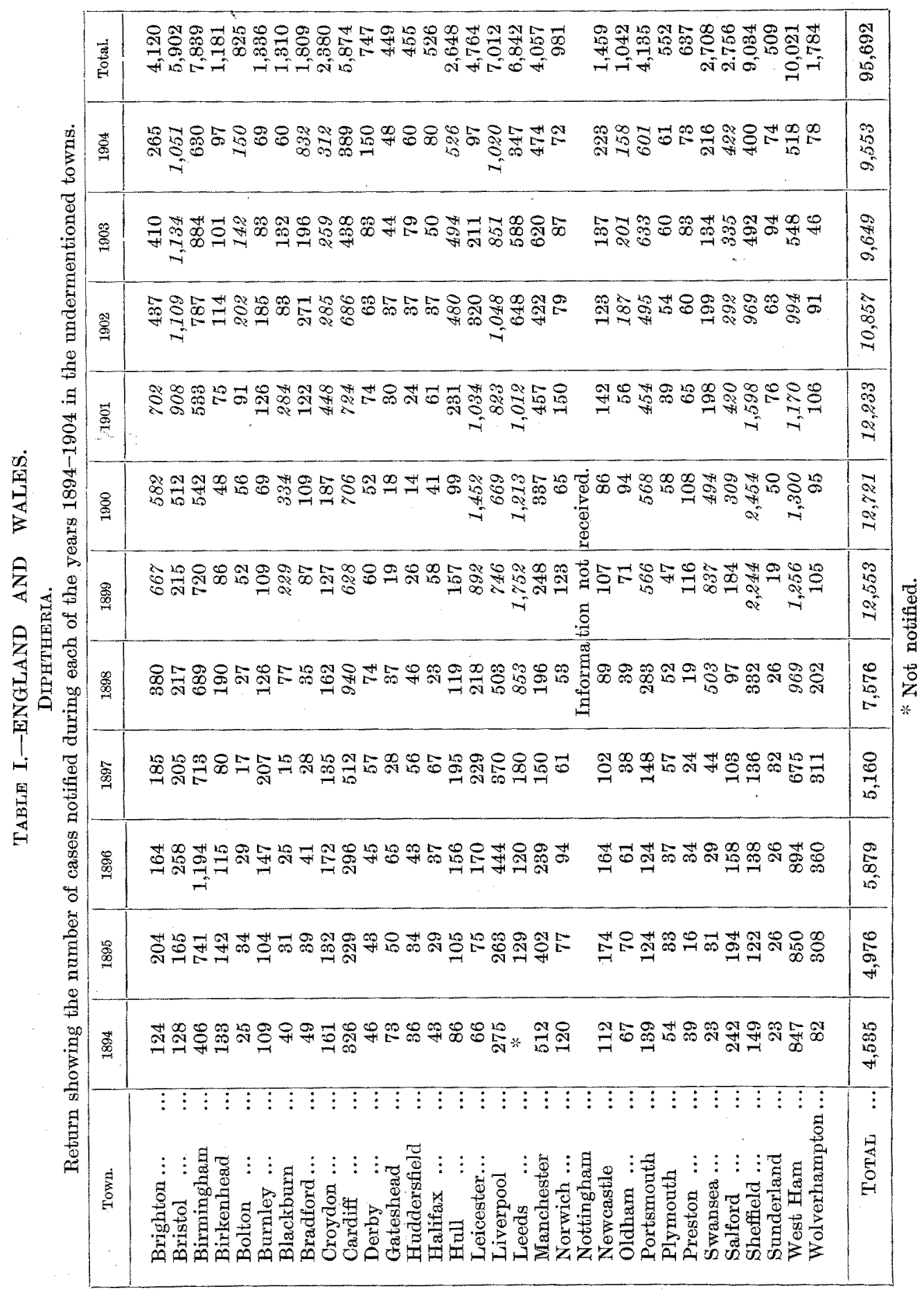


[Public Health

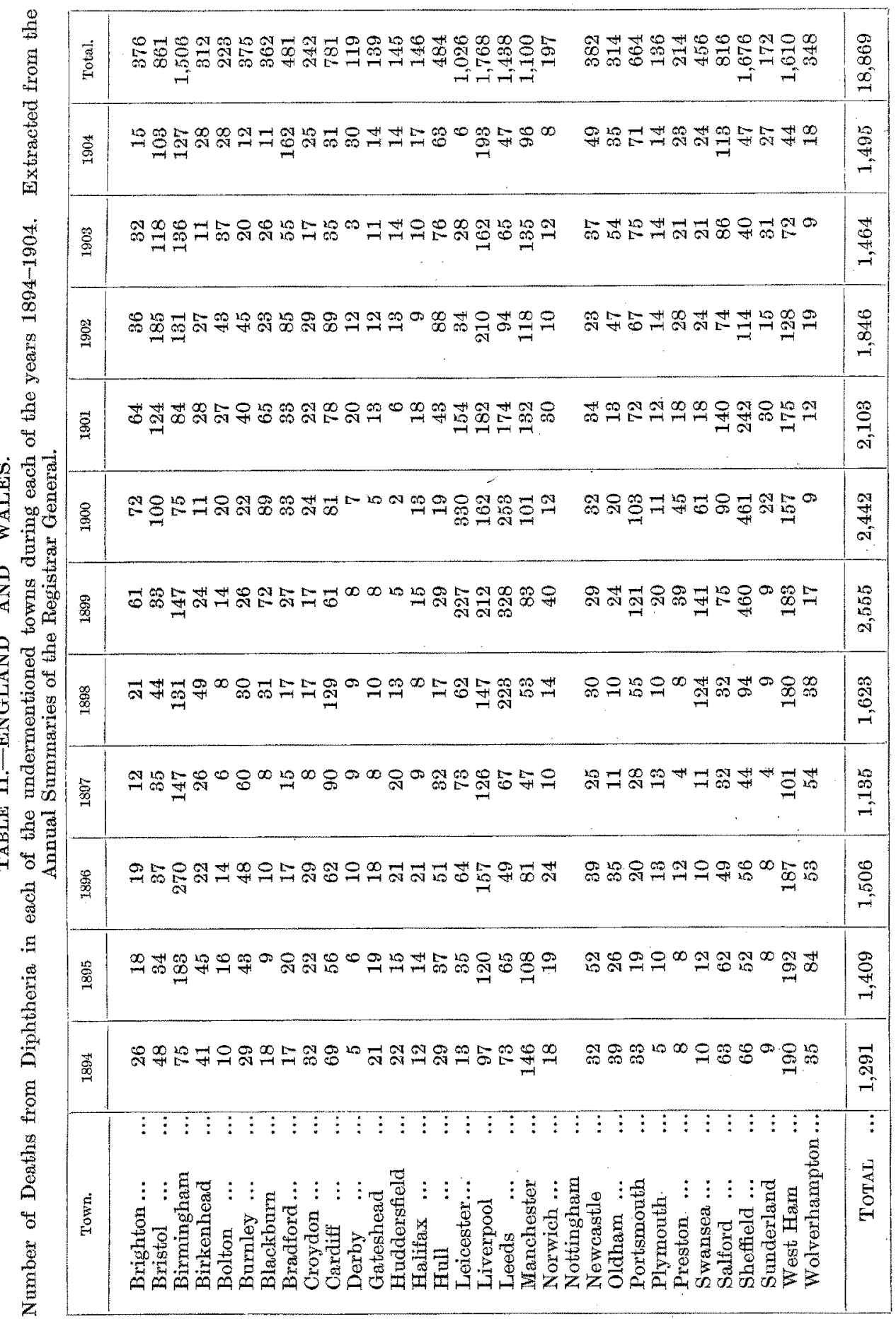




\begin{tabular}{|c|c|c|c|}
\hline 要 & 㟥 & 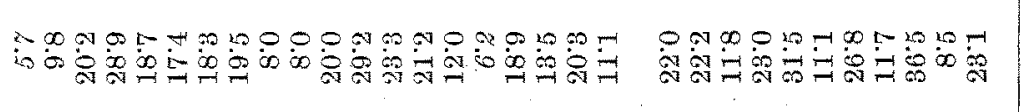 & $\stackrel{\rho}{\infty}$ \\
\hline 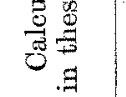 & 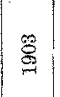 & 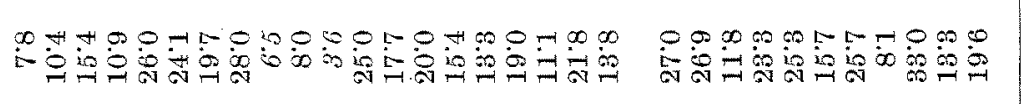 & $\stackrel{5}{5}$ \\
\hline 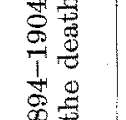 & 咅 & 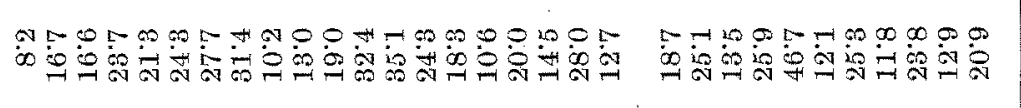 & $\stackrel{\infty}{\grave{\sigma}}$ \\
\hline 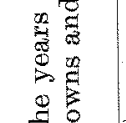 & $\overrightarrow{.}$ & 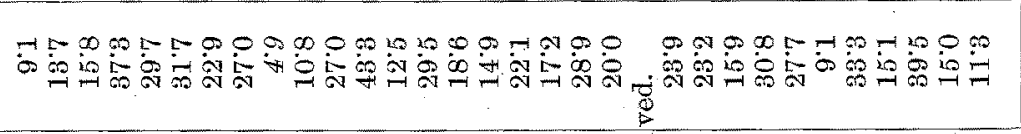 & $\stackrel{P}{\text { సิ }}$ \\
\hline 象 & 荡 & 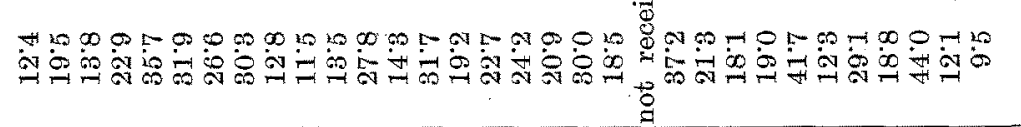 & 冷 \\
\hline 8 & $\mid$ & 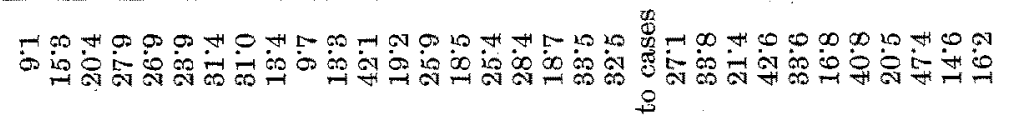 & $\begin{array}{l}\mathrm{N} \\
\text { is } \\
\text { in }\end{array}$ \\
\hline$\frac{5}{5}$ & 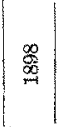 & 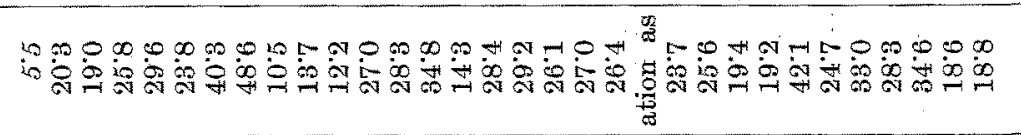 & 落 \\
\hline 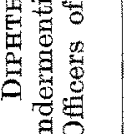 & 害 & $\begin{array}{ll}20 \\
0 \\
0\end{array}$ & $\overrightarrow{\mathrm{ig}}$ \\
\hline 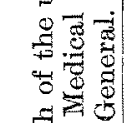 & 怘 & 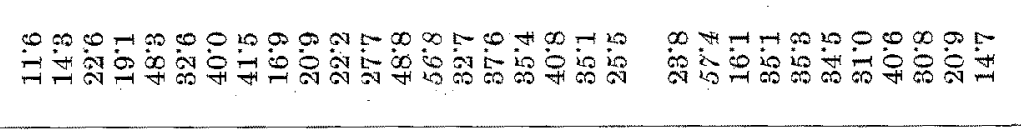 & $\underset{\infty}{\infty}$ \\
\hline 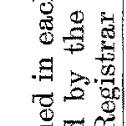 & 量 & 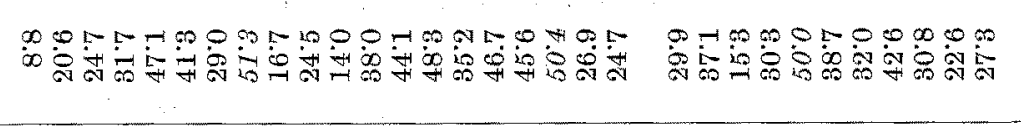 & $\bar{s}$ \\
\hline 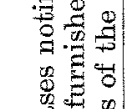 & 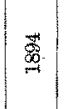 & 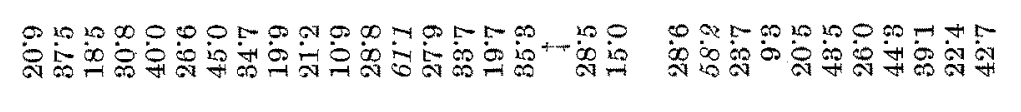 & 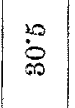 \\
\hline 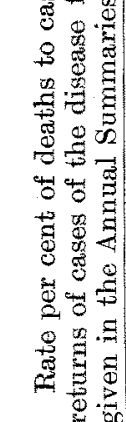 & 音 & 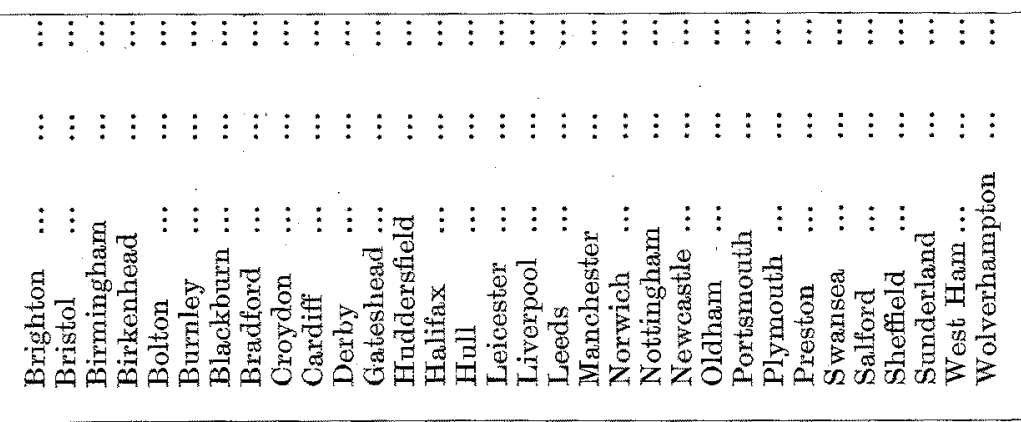 & 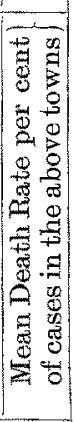 \\
\hline
\end{tabular}




\author{
TABLE IV.-LONDON.
}

\title{
DIPHTHERIA.
}

Cases treated in the Hospitals of the Metropolitan Asylums Board. Extracted from the Annual Report of the Board for 1904.

\begin{tabular}{|c|c|c|c|c|}
\hline Year. & $\begin{array}{c}\text { Total } \\
\text { Oases } \\
\text { Admitted. }\end{array}$ & $\begin{array}{c}\text { Number } \\
\text { of } \\
\text { Deaths. }\end{array}$ & $\begin{array}{l}\text { Mortality. } \\
\text { Per cent, }\end{array}$ & Remarks. \\
\hline 1888 & 99 & 46 & $59: 3$ & \\
\hline 1889 & 722 & 275 & $40^{\circ} 7$ & \\
\hline 1890 & 942 & 316 & 335 & \\
\hline 1891 & 1,312 & 397 & $30^{\circ} 6$ & \\
\hline 1892 & 2,009 & 583 & $29 \cdot 3$ & \\
\hline 1893 & 2,848 & 865 & $30^{\circ} 4$ & \\
\hline 1894 & 3,666 & 1,035 & $29 \cdot 3$ & Antitoxin first used in this year. \\
\hline 1895 & 3,635 & 820 & $22 \cdot 8$ & \\
\hline 1896 & 4,508 & 948 & 212 & $\begin{array}{l}\text { Antitoxin used in severe cases, } 66^{\circ} 2 \\
\% \text { of the whole number. }\end{array}$ \\
\hline 1897 & 5,673 & 987 & $17^{\circ} 6$ & Antitoxin used in $802 \%$ of the cases. \\
\hline 1898 & 6,566 & 991 & 153 & $\Rightarrow \quad \Rightarrow \quad 814 \% \quad$ " \\
\hline 1899 & 8,676 & 1,182 & $13 \cdot 9$ & \\
\hline 1900 & 7,873 & 988 & $12 \cdot 2$ & \\
\hline 1901 & 7,622 & 849 & 111 & In these years Antitoxin has been \\
\hline 1902 & 6,520 & 739 & $11^{\circ} 0$ & given in about $80 \%$ of the cases. \\
\hline 1903 & 5,072 & 504 & $9 \cdot 7$ & \\
\hline 1904 & 4,687 & 469 & $10^{\circ} 0$ & \\
\hline
\end{tabular}

* The Mortality Rates of Patients in the Hospitals of the Board are calculated according to the Registrar General's formula, i.e., by dividing the deaths, multiplied by 100 , by half the sum of the admissions, discharges, and deaths for the year.

Diphtheria cases have only been admitted into the Hospitals of the Board since 23rd October, 1888. The use of Antitoxic Serum in the treatment of Diphtheria began in 1894.

Average Annual Mortality per cent during the years $1888-1893 \quad 37 \cdot 3$

$$
\text { " " } \quad \text { " " , 1894-1904 15.8 }
$$

Longevity of Bacillus Typhosus in Surface Waters and Sewage. -Prof. H. L. Russell and Mr. C. A. Fuller, reported at the meeting of the American Public Health Association (September, 1905) that from their experimental work it appears that in relatively pure water of a surface character the typhoid bacillus is capable of retaining its vitality for about eight days. The results of their experiments confirm and extend on a broader basis the data obtained in the investigations made on the Chicago Drainage Canal. They have been carried out under sufficiently diverse conditions to warrant the belief that the typhoid organism does not live as long in natural sewage as it will in relatively pure water. 